\title{
Improved Ostrowski-Like Methods Based on Cubic Curve Interpolation
}

\author{
Janak Raj Sharma ${ }^{1}$, Rangan Kumar Guha ${ }^{1}$, Rajni Sharma ${ }^{2}$ \\ ${ }^{1}$ Department of Mathematics, Sant Longowal Institute of Engineering and Technology, Longowal, India \\ ${ }^{2}$ Department of Applied Sciences, D.A.V. Institute of Engineering and Technology Kabirnagar, Jalandhar, India \\ E-mail:jrshira@yahoo.co.in,rangankguha@yahoo.com,rajni_gandher@yahoo.co.in \\ Received December15, 2010; revised May 10, 2011; accepted May 13, 2011
}

\begin{abstract}
In this paper, we derive two higher order multipoint methods for solving nonlinear equations. The methodology is based on Ostrowski's method and further developed by using cubic interpolation process. The adaptation of this strategy increases the order of Ostrowski's method from four to eight and its efficiency index from 1.587 to 1.682 . The methods are compared with closest competitors in a series of numerical examples. Moreover, theoretical order of convergence is verified on the examples.
\end{abstract}

Keywords: Nonlinear Equations, Ostrowski’s Method, Root-Finding, Order of Convergence, Cubic Interpolation

\section{Introduction}

Finding the root of a non-linear equation $f(x)=0$ is a common and important problem in science and engineering. Analytic methods for solving such equations are almost non-existent and therefore, it is only possible to obtain approximate solutions by relying on numerical methods based on iteration procedures. Traub [1] has classified numerical methods into two categories viz. 1) one-point iteration methods with and without memory, and 2) multipoint iteration methods with and without memory. Two important aspects related to these classes of methods are order of convergence and computational efficiency. Order of convergence shows the speed with which a given sequence of iterates converges to the root while the computational efficiency concerns with the economy of the entire process. Investigation of one point iteration methods with and without memory, has demonstrated theoretical restrictions on the order and efficiency of these two classes of methods (see [1]). However, Kung and Traub [2] have conjectured that multipoint iteration methods without memory based on $n$ evaluations have optimal order $2^{n-1}$. In particular, with three evaluations a method of fourth order can be constructed. The well-known Ostrowski's method [3] is an example of fourth order multipoint methods without memory which is defined as

$$
\begin{gathered}
w_{i}=x_{i}-\frac{f\left(x_{i}\right)}{f^{\prime}\left(x_{i}\right)}, \\
x_{i+1}=w_{i}-\frac{f\left(w_{i}\right)}{f^{\prime}\left(x_{i}\right)} \frac{f\left(x_{i}\right)}{f\left(x_{i}\right)-2 f\left(w_{i}\right)},
\end{gathered}
$$

where $i=0,1,2, \cdots$ and $x_{0}$ is the initial approximation sufficiently close to the required root. The method requires two function $f$ and one derivative $f^{\prime}$ evaluations per step and is seen to be efficient than classical Newton's method.

Recently, based on Ostrowski's method (1) Grau and Díaz-Barrero [4] have developed a sixth order method requiring four evaluations, namely three $f$ and one $f^{\prime}$ per iteration. Sharma and Guha [5] have shown that there exists a family of such sixth order methods with equal number of evaluations.

In the present paper, we derive two modified Ostrowski's-type methods which improve the local order of convergence from four for Ostrowski's method to eight for new methods. The important feature of these methods is that per step they require three evaluations of $f$ and one evaluation of $f^{\prime}$. Thus, the new methods support the conjecture of Kung and Traub for eighth order methods based on four evaluations.

The paper is organized in six sections. In Section 2, methods are developed and their eighth order convergence is established. In Section 3, computational effi- 
ciency of the methods is discussed. Section 4 contains the numerical experimentations and comparison with some well known methods. Concluding remarks are given in Section 5. In Section 6, references are given.

\section{The Methods and Their Convergence}

\section{Method One}

Consider the Ostrowski scheme (1) now defined by

$$
\begin{aligned}
& w_{i}=x_{i}-\frac{f\left(x_{i}\right)}{f^{\prime}\left(x_{i}\right)}, \\
& z_{i}=w_{i}-\frac{f\left(w_{i}\right)}{f^{\prime}\left(x_{i}\right)} \frac{f\left(x_{i}\right)}{f\left(x_{i}\right)-2 f\left(w_{i}\right)} .
\end{aligned}
$$

In what follows, we construct the method to obtain the approximation $x_{i+1}$ to the root by considering the cubic curve interpolation. Let

$$
y(x)=a+b\left(x-x_{i}\right)+c\left(x-x_{i}\right)^{2}+d\left(x-x_{i}\right)^{3},
$$

be an interpolatory polynomial of degree three such that

$$
\begin{gathered}
y\left(x_{i}\right)=f\left(x_{i}\right), \\
y^{\prime}\left(x_{i}\right)=f^{\prime}\left(x_{i}\right), \\
y\left(w_{i}\right)=f\left(w_{i}\right), \\
y\left(z_{i}\right)=f\left(z_{i}\right),
\end{gathered}
$$

and

$$
y^{\prime}\left(z_{i}\right) \approx f^{\prime}\left(z_{i}\right) .
$$

Our interest is to find the unknown parameters $a, b, c$ and $d$ introduced in the polynomial. In order to achieve that, we make use of the expressions (4) - (7) in (3). From (3), (4) and (5), it is easy to show that

$$
\begin{aligned}
& a=f\left(x_{i}\right), \\
& b=f^{\prime}\left(x_{i}\right) .
\end{aligned}
$$

Substituting the values of $a$ and $b$ in (3) then using (6) and (7), we obtain after some simple calculations

$$
\begin{gathered}
c+d\left(w_{i}-x_{i}\right)=\frac{1}{w_{i}-x_{i}}\left[\frac{f\left(w_{i}\right)-f\left(x_{i}\right)}{w_{i}-x_{i}}-f^{\prime}\left(x_{i}\right)\right], \\
c+d\left(z_{i}-x_{i}\right)=\frac{1}{z_{i}-x_{i}}\left[\frac{f\left(z_{i}\right)-f\left(x_{i}\right)}{z_{i}-x_{i}}-f^{\prime}\left(x_{i}\right)\right] .
\end{gathered}
$$

Solving these equations using Ostrowski iteration (2), we obtain

$$
c=\frac{f^{\prime 2}\left(x_{i}\right)}{f^{2}\left(x_{i}\right)}\left[f\left(w_{i}\right)+\frac{f\left(x_{i}\right)-2 f\left(w_{i}\right)}{f\left(w_{i}\right) f\left(x_{i}\right)-f\left(w_{i}\right)^{2}} H\right],
$$

$$
d=\frac{f^{\prime 3}\left(x_{i}\right)}{f^{3}\left(x_{i}\right)} \frac{f\left(x_{i}\right)-2 f\left(w_{i}\right)}{f\left(w_{i}\right)\left(f\left(x_{i}\right)-f\left(w_{i}\right)\right)^{2}} H,
$$

where

$$
\begin{aligned}
H & =f\left(x_{i}\right) f\left(w_{i}\right)\left(f\left(x_{i}\right)-f\left(w_{i}\right)\right)-\left(f\left(x_{i}\right)-f\left(w_{i}\right)\right)^{3} . \\
& +\left(f\left(x_{i}\right)-f\left(z_{i}\right)\right)\left(f\left(x_{i}\right)-2 f\left(w_{i}\right)\right)^{2} .
\end{aligned}
$$

The tangent line to the curve of cubic polynomial (3) at the point $\left(z_{i}, y\left(z_{i}\right)\right)$ is given by

$$
y-y\left(z_{i}\right)=y^{\prime}\left(z_{i}\right)\left(x-z_{i}\right) .
$$

Assuming that the root estimate $x_{i+1}$ is point of intersection of the tangent line (14) with $x$-axis, then $y\left(x_{i+1}\right)=0$. Thus, from (7), (8) and (14), we obtain

$$
x_{i+1}=z_{i}-\frac{f\left(z_{i}\right)}{y^{\prime}\left(z_{i}\right)} .
$$

Now using the approximation (8) in (15), we can obtain the new improvement as given by

$$
x_{i+1}=z_{i}-\frac{f\left(z_{i}\right)}{f^{\prime}\left(z_{i}\right)} .
$$

where $z_{i}$ is the Ostrowski point. It is quite obvious that formula (16) together with (2) requires five evaluations per iteration. However, we can reduce the number of evaluations to four by utilizing the approximation (8). Therefore, (3) and (8) yield

$$
f^{\prime}\left(z_{i}\right) \approx y^{\prime}\left(z_{i}\right)=b+2 c\left(z_{i}-x_{i}\right)+3 d\left(z_{i}-x_{i}\right)^{2} .
$$

Substituting the values of $b$, c and $d$ in (17), we obtain

where

$$
f^{\prime}\left(z_{i}\right) \approx y^{\prime}\left(z_{i}\right)=\phi f^{\prime}\left(x_{i}\right),
$$

$$
\begin{aligned}
\phi & =\left[f\left(w_{i}\right)\left(f\left(w_{i}\right)-f\left(x_{i}\right)\right)^{3}-f\left(x_{i}\right) f\left(z_{i}\right)\left(f\left(w_{i}\right)\right.\right. \\
& \left.-f\left(x_{i}\right)\right)\left(f\left(x_{i}\right)-2 f\left(w_{i}\right)\right)-2 f^{2}\left(w_{i}\right)\left(f\left(z_{i}\right)\right. \\
& \left.\left.-f\left(x_{i}\right)\right)\left(f\left(x_{i}\right)-2 f\left(w_{i}\right)\right)\right] \\
& \times\left[f\left(x_{i}\right) f\left(w_{i}\right)\left(f\left(w_{i}\right)-f\left(x_{i}\right)\right)\left(f\left(x_{i}\right)-2 f\left(w_{i}\right)\right)\right]^{-1} .
\end{aligned}
$$

Then the formula (16) in its final form is given by

$$
x_{i+1}=z_{i}-(\phi)^{-1} \frac{f\left(z_{i}\right)}{f^{\prime}\left(x_{i}\right)},
$$

where $z_{i}$ is the Ostrowski iteration (2) and $\phi$ is given in (18).

Thus, we derive a multipoint method based on the composition of two sub steps, Ostrowski sub step (2) followed by (19) obtained by tangential cubic interpolation. It is straight forward to see that per step the method util- 
izes four pieces of information namely- $f\left(x_{i}\right), f^{\prime}\left(x_{i}\right)$, $f\left(w_{i}\right)$ and $f\left(z_{i}\right)$. Since we are using the approximation (8) for the derivative, therefore the error is given by (see [6])

$$
f^{\prime}\left(z_{i}\right)-y^{\prime}\left(z_{i}\right)=\frac{f^{(i v)}(\xi)}{4 !}\left(z_{i}-x_{i}\right)^{2}\left(z_{i}-w_{i}\right)
$$

where $\xi \in\left[\min \left\{x_{i}, w_{i}, z_{i}\right\}, \max \left\{x_{i}, w_{i}, z_{i}\right\}\right]$. In order to show that the method is of order eight, we prove the following theorem:
Theorem 1. Let $f(x)$ be a real valued function. Assuming that $f(x)$ is sufficiently smooth in an interval I. If $f(x)$ has a simple root $\alpha \in I$ and $x_{0}$ is sufficiently close to $\alpha$ then the method defined by (19) is of order eight.

Proof: Let $e_{i}=x_{i}-\alpha, \quad \tilde{e}_{i}=w_{i}-\alpha$ and $\hat{e}_{i}=z_{i}-\alpha$ be errors in the ith iteration. Using Taylor's series expansion of $f\left(x_{i}\right)$ about $\alpha$ and taking into account that $f(\alpha)=0$ and $f^{\prime}(\alpha) \neq 0$, we have

$$
f\left(x_{i}\right)=f^{\prime}(\alpha)\left[e_{i}+A_{2} e_{i}^{2}+A_{3} e_{i}^{3}+A_{4} e_{i}^{4}+A_{5} e_{i}^{5}+A_{6} e_{i}^{6}+O\left(e_{i}^{7}\right)\right],
$$

where $\quad A_{k}=(1 / k !) f^{(k)}(\alpha) / f^{\prime}(\alpha), \quad k=2,3, \cdots$

Furthermore, we have

$$
\begin{gathered}
f^{\prime}\left(x_{i}\right)=f^{\prime}(\alpha)\left[1+2 A_{2} e_{i}+3 A_{3} e_{i}^{2}+4 A_{4} e_{i}^{3}+5 A_{5} e_{i}^{4}+6 A_{6} e_{i}^{5}+O\left(e_{i}^{6}\right)\right] . \\
\frac{f\left(x_{i}\right)}{f^{\prime}\left(x_{i}\right)}=e_{i}-A_{2} e_{i}^{2}-2\left(A_{3}-A_{2}^{2}\right) e_{i}^{3}-\left(3 A_{4}-7 A_{3} A_{2}+4 A_{2}^{3}\right) e_{i}^{4}-\left(4 A_{5}-10 A_{4} A_{2}-6 A_{3}^{2}+20 A_{3} A_{2}^{2}-8 A_{2}^{4}\right) e_{i}^{5} \\
-\left(5 A_{6}-13 A_{5} A_{2}-17 A_{4} A_{3}+28 A_{4} A_{2}^{2}+33 A_{3}^{2} A_{2}-52 A_{3} A_{2}^{3}+16 A_{2}^{5}\right) e_{i}^{6}+O\left(e_{i}^{7}\right) .
\end{gathered}
$$

Substitution of (23) in first step of (2), yields

$$
\begin{aligned}
\tilde{e}_{i} & =A_{2} e_{i}^{2}+2\left(A_{3}-A_{2}^{2}\right) e_{i}^{3}+\left(3 A_{4}-7 A_{3} A_{2}+4 A_{2}^{3}\right) e_{i}^{4}+\left(4 A_{5}-10 A_{4} A_{2}-6 A_{3}^{2}+20 A_{3} A_{2}^{2}-8 A_{2}^{4}\right) e_{i}^{5} \\
& +\left(5 A_{6}-13 A_{5} A_{2}-17 A_{4} A_{3}+28 A_{4} A_{2}^{2}+33 A_{3}^{2} A_{2}-52 A_{3} A_{2}^{3}+16 A_{2}^{5}\right) e_{i}^{6}+O\left(e_{i}^{7}\right) .
\end{aligned}
$$

Expanding $f\left(w_{i}\right)$ about $\alpha$ and using (24), we obtain

$$
\begin{aligned}
& f\left(w_{i}\right)=f^{\prime}(\alpha)\left[A_{2} e_{i}^{2}+2\left(A_{3}-A_{2}^{2}\right) e_{i}^{3}+\left(3 A_{4}-7 A_{3} A_{2}+5 A_{2}^{3}\right) e_{i}^{4}+\left(4 A_{5}-10 A_{4} A_{2}-6 A_{3}^{2}+24 A_{3} A_{2}^{2}-12 A_{2}^{4}\right) e_{i}^{5}\right. \\
& \left.+\left(5 A_{6}-13 A_{5} A_{2}-17 A_{4} A_{3}+34 A_{4} A_{2}^{2}+37 A_{3}^{2} A_{2}-73 A_{3} A_{2}^{3}+28 A_{2}^{5}\right) e_{i}^{6}+O\left(e_{i}^{7}\right)\right] .
\end{aligned}
$$

Using Equations (21), (23) and (25), we obtain

$$
\begin{aligned}
\frac{f\left(x_{i}\right)}{f^{\prime}\left(x_{i}\right)} \frac{f\left(w_{i}\right)}{f\left(x_{i}\right)-2 f\left(w_{i}\right)} & =A_{2} e_{i}^{2}+\left(2 A_{3}-2 A_{2}^{2}\right) e_{i}^{3}+\left(3 A_{4}-6 A_{3} A_{2}+3 A_{2}^{3}\right) e_{i}^{4}+\left(4 A_{5}-8 A_{4} A_{2}-4 A_{3}^{2}+12 A_{3} A_{2}^{2}-4 A_{2}^{4}\right) e_{i}^{5} \\
& +\left(5 A_{6}-10 A_{5} A_{2}-10 A_{4} A_{3}+16 A_{4} A_{2}^{2}+15 A_{3}^{2} A_{2}-22 A_{3} A_{2}^{3}+6 A_{2}^{5}\right) e_{i}^{6}+O\left(e_{i}^{7}\right) .
\end{aligned}
$$

From second step of (2) it follows that

$$
\begin{aligned}
& \hat{e}_{i}=\left(A_{2}^{3}-A_{3} A_{2}\right) e_{i}^{4}+\left(-2 A_{4} A_{2}-2 A_{3}^{2}+8 A_{3} A_{2}^{2}-4 A_{2}^{4}\right) e_{i}^{5} \\
& +\left(-3 A_{5} A_{2}-7 A_{4} A_{3}+12 A_{4} A_{2}^{2}+18 A_{3}^{2} A_{2}-30 A_{3} A_{2}^{3}+10 A_{2}^{5}\right) e_{i}^{6}+O\left(e_{i}^{7}\right) .
\end{aligned}
$$

Expanding $f\left(z_{i}\right)$ about $\alpha$, we obtain

$$
f\left(z_{i}\right)=f^{\prime}(\alpha)\left[\hat{e}_{i}+A_{2} \hat{e}_{i}^{2}+O\left(e_{i}^{9}\right)\right],
$$

Using (27) in (28), we get 


$$
\begin{aligned}
f\left(z_{i}\right) & =f^{\prime}(\alpha)\left[\left(A_{2}^{3}-A_{3} A_{2}\right) e_{i}^{4}+\left(-2 A_{4} A_{2}-2 A_{3}^{2}+8 A_{3} A_{2}^{2}-4 A_{2}^{4}\right) e_{i}^{5}\right. \\
& \left.+\left(-3 A_{5} A_{2}-7 A_{4} A_{3}+12 A_{4} A_{2}^{2}+18 A_{3}^{2} A_{2}-30 A_{3} A_{2}^{3}+10 A_{2}^{5}\right) e_{i}^{6}+O\left(e_{i}^{7}\right)\right] .
\end{aligned}
$$

Using the results of (21), (25) and (29) in

$$
\begin{aligned}
& \phi=\left[f\left(w_{i}\right)\left(f\left(w_{i}\right)-f\left(x_{i}\right)\right)^{3}-f\left(x_{i}\right) f\left(z_{i}\right)\left(f\left(w_{i}\right)-f\left(x_{i}\right)\right)\left(f\left(x_{i}\right)-2 f\left(w_{i}\right)\right)\right. \\
& \left.-2 f^{2}\left(w_{i}\right)\left(f\left(z_{i}\right)-f\left(x_{i}\right)\right)\left(f\left(x_{i}\right)-2 f\left(w_{i}\right)\right)\right]\left[f\left(x_{i}\right) f\left(w_{i}\right)\left(f\left(w_{i}\right)-f\left(x_{i}\right)\right)\left(f\left(x_{i}\right)-2 f\left(w_{i}\right)\right)\right]^{-1},
\end{aligned}
$$

and simplifying, we get

$$
\phi=1-2 A_{2} e_{i}+\left(4 A_{2}^{2}-3 A_{3}\right) e_{i}^{2}-\left(4 A_{4}-12 A_{3} A_{2}+8 A_{2}^{3}\right) e_{i}^{3}+\left(-5 A_{5}+17 A_{4} A_{2}+9 A_{3}^{2}-38 A_{3} A_{2}^{2}+18 A_{2}^{4}\right) e_{i}^{4}+O\left(e_{i}^{5}\right) .
$$

From (22) and (30), we get

$$
\phi f^{\prime}\left(x_{i}\right)=f^{\prime}(\alpha)\left[1+A_{2}\left(A_{4}-2 A_{3} A_{2}+2 A_{2}^{3}\right) e_{i}^{4}+O\left(e_{i}^{5}\right)\right]
$$

Using (28) and (31) in $x_{i+1}=z_{i}-(\phi)^{-1} \frac{f\left(z_{i}\right)}{f^{\prime}\left(x_{i}\right)}$, we find the error equation as given by

$$
\begin{aligned}
e_{i+1} & =\hat{e}_{i}-\frac{\left[\hat{e}_{i}+A_{2} \hat{e}_{i}^{2}+O\left(e_{i}^{9}\right)\right]}{\left[1+A_{2}\left(A_{4}-2 A_{3} A_{2}+2 A_{2}^{3}\right) e_{i}^{4}+O\left(e_{i}^{5}\right)\right]}=\hat{e}_{i}-\left[\hat{e}_{i}+A_{2} \hat{e}_{i}^{2}\right]\left[1-A_{2}\left(A_{4}-2 A_{3} A_{2}+2 A_{2}^{3}\right) e_{i}^{4}\right]+O\left(e_{i}^{9}\right) \\
& =-\left[A_{2} \hat{e}_{i}^{2}-A_{2}\left(A_{4}-2 A_{3} A_{2}+2 A_{2}^{3}\right) e_{i}^{4} \hat{e}_{i}\right]+O\left(e_{i}^{9}\right) \\
& =-\left[A_{2}\left(A_{2}^{3}-A_{3} A_{2}\right)^{2}-A_{2}\left(A_{4}-2 A_{3} A_{2}+2 A_{2}^{3}\right)\left(A_{2}^{3}-A_{3} A_{2}\right)\right] e_{i}^{8}+O\left(e_{i}^{9}\right) \\
& =A_{2}^{2}\left(A_{2}^{2}-A_{3}\right)\left[A_{2}\left(A_{2}^{2}-A_{3}\right)+A_{4}\right] e_{i}^{8}+O\left(e_{i}^{9}\right) .
\end{aligned}
$$

Thus Equation (32) establishes the maximum order of convergence equal to eight for the iteration scheme defined by (19). This completes the proof of the theorem.

Remark 1. The error (20) is now given by

$$
f^{\prime}\left(z_{i}\right)-y^{\prime}\left(z_{i}\right)=\frac{f^{(i v)}(\xi)}{4 !}\left(\hat{e}_{i}-e_{i}\right)^{2}\left(\hat{e}_{i}-\tilde{e}_{i}\right) .
$$

From (24), (27) and Taylor's expansion of $f^{(i v)}(\xi)$ about $\alpha$, we can obtain the error as

$$
f^{\prime}\left(z_{i}\right)-y^{\prime}\left(z_{i}\right)=-A_{4} A_{2} e_{i}^{4}+O\left(e_{i}^{5}\right) .
$$

This shows that the error in derivative approximation is of order four.

Remark 2. Upon using Taylor's expansion

$$
\begin{gathered}
f^{\prime}\left(z_{i}\right)=f^{\prime}(\alpha)\left[1+2 A_{2} \hat{e}_{i}+O\left(\hat{e}_{i}^{2}\right)\right] \text { in (33), we get } \\
y^{\prime}\left(z_{i}\right)=f^{\prime}(\alpha)\left[1+2 A_{2} \hat{e}_{i}+A_{4} A_{2} e_{i}^{4}+O\left(e_{i}^{5}\right)\right],
\end{gathered}
$$

that is

$$
\begin{aligned}
& y^{\prime}\left(z_{i}\right) \\
& =f^{\prime}(\alpha)\left[1+A_{2}\left(A_{4}-2 A_{3} A_{2}+2 A_{2}^{3}\right) e_{i}^{4}+O\left(e_{i}^{5}\right)\right],
\end{aligned}
$$

which is same as obtained in equation (31) of $y^{\prime}\left(z_{i}\right)=\phi f^{\prime}\left(x_{i}\right)$. This verifies the correctness of error (33) and calculation of $y^{\prime}\left(z_{i}\right)$.

Remark 3. From the convergence theorem of iterative functions [1], if $g_{1}(x)$ and $g_{2}(x)$ are two iterative functions of order $p_{1}$ and $p_{2}$, respectively, then the new composite iterative function $G(x)=g_{2}\left(g_{1}(x)\right)$ has the order $p_{1} p_{2}$. In our case, the Ostrowski method (2) comprising the first two steps, is of order four. Thus to produce eighth order method the formula (19) should be of order two (neglecting how $z_{i}$ is obtained). From (34), it turns out that $y^{\prime}\left(z_{i}\right)=\phi f^{\prime}\left(x_{i}\right)=f^{\prime}(\alpha)\left[1+O\left(\hat{e}_{i}\right)\right]$. Also, the Taylor's series expansion of the function $f\left(z_{i}\right)=f^{\prime}(\alpha)\left[\hat{e}_{i}+A_{2} \hat{e}_{i}^{2}+O\left(\hat{e}_{i}^{3}\right)\right]$. On substitution and simplifying, we see that the Newton-like method (15) and hence (19), has the order two, thus verifying the convergence theorem on composition of two iterative functions to produce eighth order iterative method.

\subsection{Method Two}

Here we consider the inverse interpolation. Let 


$$
\begin{aligned}
F(f(x)) & =A+B\left(f(x)-f\left(x_{i}\right)\right) \\
& +C\left(f(x)-f\left(x_{i}\right)\right)^{2} \\
& +D\left(f(x)-f\left(x_{i}\right)\right)^{3},
\end{aligned}
$$

be an inverse interpolatory polynomial of degree three such that

$$
\begin{gathered}
F\left(f\left(x_{i}\right)\right)=x_{i}, \\
F^{\prime}\left(f\left(x_{i}\right)\right) f^{\prime}\left(x_{i}\right)=1, \\
F\left(f\left(w_{i}\right)\right)=w_{i}, \\
F\left(f\left(z_{i}\right)\right)=z_{i},
\end{gathered}
$$

and

$$
F^{\prime}\left(f\left(z_{i}\right)\right) f^{\prime}\left(z_{i}\right) \approx 1 .
$$

From (36) and (37), we can calculate $A$ and $B$ as given by

$$
A=x_{i}, B=1 / f^{\prime}\left(x_{i}\right) .
$$

Substituting the values of $A$ and $B$ in (35), then using (38) and (39), we obtain

$$
\begin{aligned}
& C+D\left(f\left(w_{i}\right)-f\left(x_{i}\right)\right) \\
& =-\frac{1}{\left(f\left(w_{i}\right)-f\left(x_{i}\right)\right)^{2}} \frac{f\left(w_{i}\right)}{f^{\prime}\left(x_{i}\right)}
\end{aligned}
$$

and

$$
\begin{aligned}
& C+D\left(f\left(z_{i}\right)-f\left(x_{i}\right)\right)=-\frac{1}{\left(f\left(z_{i}\right)-f\left(x_{i}\right)\right)^{2}} \\
& \times\left[\frac{f\left(w_{i}\right)}{f^{\prime}\left(x_{i}\right)} \frac{f\left(x_{i}\right)}{f\left(x_{i}\right)-2 f\left(w_{i}\right)}+\frac{f\left(z_{i}\right)}{f^{\prime}\left(x_{i}\right)}\right] .
\end{aligned}
$$

The Equations (42) and (43) when solved, yield

$$
\begin{gathered}
C=-\frac{1}{\left(f\left(w_{i}\right)-f\left(x_{i}\right)\right)^{2}} \frac{f\left(w_{i}\right)}{f^{\prime}\left(x_{i}\right)} \\
-\frac{1}{f^{\prime}\left(x_{i}\right)} \frac{f\left(w_{i}\right)-f\left(x_{i}\right)}{f\left(w_{i}\right)-f\left(z_{i}\right)} G, \\
D=\frac{1}{f^{\prime}\left(x_{i}\right)\left(f\left(w_{i}\right)-f\left(z_{i}\right)\right)} G,
\end{gathered}
$$

where

$$
\begin{aligned}
G & =-\frac{f\left(w_{i}\right)}{\left(f\left(w_{i}\right)-f\left(x_{i}\right)\right)^{2}} \\
& +\frac{1}{\left(f\left(z_{i}\right)-f\left(x_{i}\right)\right)^{2}}\left[f\left(z_{i}\right)+\frac{f\left(x_{i}\right) f\left(w_{i}\right)}{f\left(x_{i}\right)-2 f\left(w_{i}\right)}\right] .
\end{aligned}
$$

The tangent line to the curve of cubic polynomial (35) at the point $\left(F\left(f\left(z_{i}\right)\right), f\left(z_{i}\right)\right)$ is given by

$$
F(f(x))-F\left(f\left(z_{i}\right)\right)=F^{\prime}\left(f\left(z_{i}\right)\right)\left(f(x)-f\left(z_{i}\right)\right) .
$$

The approximation to the root $x_{i+1}$ is now obtained by intersecting this tangent line with $\mathrm{x}$-axis. This yields

$$
x_{i+1}=z_{i}-\frac{f\left(z_{i}\right)}{f^{\prime}\left(z_{i}\right)},
$$

where

$$
\begin{aligned}
f^{\prime}\left(z_{i}\right) & \approx 1 / F^{\prime}\left(f\left(z_{i}\right)\right) \\
& =\left[B+2 C\left(f\left(z_{i}\right)-f\left(x_{i}\right)\right)\right. \\
& \left.+3 D\left(f\left(z_{i}\right)-f\left(x_{i}\right)\right)^{2}\right]^{-1} .
\end{aligned}
$$

From (40), (44) and (45), we have

$$
\frac{1}{f^{\prime}\left(z_{i}\right)}=\psi \frac{1}{f^{\prime}\left(x_{i}\right)},
$$

where

$$
\begin{aligned}
\psi & =1-\frac{f\left(w_{i}\right)}{f\left(w_{i}\right)-f\left(z_{i}\right)}\left[\frac{f\left(z_{i}\right)-f\left(x_{i}\right)}{f\left(w_{i}\right)-f\left(z_{i}\right)}\right]^{2} \\
& +\left[\frac{1}{f\left(w_{i}\right)-f\left(z_{i}\right)}-\frac{2}{f\left(z_{i}\right)-f\left(x_{i}\right)}\right] \\
& \times\left[f\left(z_{i}\right)+\frac{f\left(x_{i}\right) f\left(w_{i}\right)}{f\left(w_{i}\right)-2 f\left(w_{i}\right)}\right] .
\end{aligned}
$$

Hence, the iteration formula (46) is given by

$$
x_{i+1}=z_{i}-\psi \frac{f\left(z_{i}\right)}{f^{\prime}\left(x_{i}\right)},
$$

where $z_{i}$ is the Ostrowski iteration (2) and $\psi$ is shown in (47).

Thus, we obtain second modified Ostrowski-like method (48) developed by tangential inverse interpolation. In this method also, the number of evaluations required is same as in the first method. Error in the approximation (40), likewise the error (20), can be given by

$$
\begin{aligned}
& \frac{1}{f^{\prime}\left(z_{i}\right)}-F^{\prime}\left(f\left(z_{i}\right)\right) \\
= & \frac{f^{(i v)}(\eta)}{4 !}\left(f\left(z_{i}\right)-f\left(x_{i}\right)\right)^{2}\left(f\left(z_{i}\right)-f\left(w_{i}\right)\right),
\end{aligned}
$$

where

$$
\begin{gathered}
\eta \in\left[\min \left\{f\left(x_{i}\right), f\left(w_{i}\right), f\left(z_{i}\right)\right\},\right. \\
\left.\max \left\{f\left(x_{i}\right), f\left(w_{i}\right), f\left(z_{i}\right)\right\}\right] .
\end{gathered}
$$


In the following theorem we prove that the method is of order eight.

Theorem 2. Under the hypotheses of theorem 1, the it- eration method defined by (48) is of order eight.

Proof: Using (21), (25) and (29), after simple calculations we find

$$
\begin{aligned}
& {\left[\frac{1}{f\left(w_{i}\right)-f\left(z_{i}\right)}-\frac{2}{f\left(z_{i}\right)-f\left(x_{i}\right)}\right]\left[f\left(z_{i}\right)+\frac{f\left(w_{i}\right) f\left(x_{i}\right)}{f\left(x_{i}\right)-2 f\left(w_{i}\right)}\right]} \\
& =1+4 A_{2} e_{i}+\left(6 A_{3}-2 A_{2}^{2}\right) e_{i}^{2}+\left(8 A_{4}-4 A_{3} A_{2}\right) e_{i}^{3}+\left(10 A_{5}-6 A_{4} A_{2}+2 A_{2}^{2} A_{3}-2 A_{2}^{4}\right) e_{i}^{4}+O\left(e_{i}^{5}\right) .
\end{aligned}
$$

Also

$$
\begin{aligned}
& \frac{f\left(w_{i}\right)}{f\left(w_{i}\right)-f\left(z_{i}\right)}\left[\frac{f\left(z_{i}\right)-f\left(x_{i}\right)}{f\left(w_{i}\right)-f\left(x_{i}\right)}\right]^{2} \\
& =1+2 A_{2} e_{i}+\left(3 A_{3}-2 A_{2}^{2}\right) e_{i}^{2}+\left(4 A_{4}-4 A_{3} A_{2}\right) e_{i}^{3}+5\left(A_{6}-A_{4} A_{2}-A_{2}^{2} A_{3}+A_{2}^{4}\right) e_{i}^{4}+O\left(e_{i}^{5}\right) .
\end{aligned}
$$

From (47) we know $\psi=1+$ Equation (50) - Equation (51), which implies

$$
\psi=1+2 A_{2} e_{i}+3 A_{3} e_{i}^{2}+4 A_{4} e_{i}^{3}+\left(5 A_{5}-A_{4} A_{2}+7 A_{3} A_{2}^{2}-7 A_{2}^{4}\right) e_{i}^{4}+O\left(e_{i}^{5}\right) .
$$

From (22) and (52), we get

$$
\frac{\psi}{f^{\prime}\left(x_{i}\right)}=\frac{1}{f^{\prime}(\alpha)}\left[1+A_{2}\left(-A_{4}+7 A_{3} A_{2}-7 A_{2}^{3}\right) e_{i}^{4}+O\left(e_{i}^{5}\right)\right]
$$

Then using (28) and (53) in $x_{i+1}=z_{i}-\psi \frac{f\left(z_{i}\right)}{f^{\prime}\left(x_{i}\right)}$, we obtain the error equation

$$
\begin{aligned}
e_{i+1} & =\hat{e}_{i}-\left[\hat{e}_{i}+A_{2} \hat{e}_{i}^{2}+O\left(e_{i}^{9}\right)\right]\left[1+\left(-A_{4} A_{2}+7 A_{2}^{2} A_{3}-7 A_{2}^{4}\right) e_{i}^{4}+O\left(e_{i}^{5}\right)\right] \\
& =\hat{e}_{i}-\left[\hat{e}_{i}+A_{2} \hat{e}_{i}^{2}\right]\left[1+\left(-A_{4} A_{2}+7 A_{2}^{2} A_{3}-7 A_{2}^{4}\right) e_{i}^{4}\right]+O\left(e_{i}^{9}\right) \\
& =-\left[A_{2} \hat{e}_{i}^{2}+A_{2}\left(-A_{4}+7 A_{3} A_{2}-7 A_{2}^{3}\right) e_{i}^{4} \hat{e}_{i}\right]+O\left(e_{i}^{9}\right) \\
& =-\left[A_{2}\left(A_{2}^{3}-A_{3} A_{2}\right)^{2}+A_{2}\left(-A_{4}+7 A_{3} A_{2}-7 A_{2}^{3}\right)\left(A_{2}^{3}-A_{3} A_{2}\right)\right] e_{i}^{8}+O\left(e_{i}^{9}\right) \\
& =A_{2}^{2}\left(A_{2}^{2}-A_{3}\right)\left[6 A_{2}\left(A_{2}^{2}-A_{3}\right)+A_{4}\right] e_{i}^{8}+O\left(e_{i}^{9}\right) .
\end{aligned}
$$

This result shows the eighth order convergence of method (48).

Remark 4. The error (49) upon using (21), (25) and (29) is given by

$$
\begin{aligned}
& \frac{1}{f^{\prime}\left(z_{i}\right)}-F^{\prime}\left(f\left(z_{i}\right)\right) \\
= & \frac{F^{(i v)}(\eta)}{4 !}\left[-\left(f^{\prime}(\alpha)\right)^{3} A_{2} e_{i}^{4}+O\left(e_{i}^{5}\right)\right] .
\end{aligned}
$$

Expanding $F^{(i v)}(\eta)$ about $\alpha$ and using the fact that

$$
\begin{aligned}
F^{(i v)}(0) & =\frac{-15\left(f^{\prime \prime}(\alpha)\right)^{3}}{\left(f^{\prime}(\alpha)\right)^{7}}+\frac{10 f^{\prime \prime}(\alpha) f^{\prime \prime \prime}(\alpha)}{\left(f^{\prime}(\alpha)\right)^{6}}-\frac{f^{(i v)}(\alpha)}{\left(f^{\prime}(\alpha)\right)^{5}} \\
& =\frac{4 !}{\left(f^{\prime}(\alpha)\right)^{4}}\left[-5 A_{2}^{3}+5 A_{3} A_{2}-A_{4}\right],
\end{aligned}
$$

we can obtain the error as

$$
\begin{aligned}
& \frac{1}{f^{\prime}\left(z_{i}\right)}-F^{\prime}\left(f\left(z_{i}\right)\right) \\
& =\frac{1}{f^{\prime}(\alpha)} A_{2}\left[A_{4}-5 A_{3} A_{2}+5 A_{2}^{3}\right] e_{i}^{4}+O\left(e_{i}^{5}\right) .
\end{aligned}
$$

This shows that the error in approximation (40) is of order four.

Remark 5. Upon using Taylor's expansion $1 / f^{\prime}\left(z_{i}\right)$ $=\left[1 / f^{\prime}(\alpha)\right]\left[1-2 A_{2} \hat{e}_{i}+O\left(\hat{e}_{i}^{2}\right)\right]$ in (55), we get

$$
\begin{aligned}
& F^{\prime}\left(f\left(z_{i}\right)\right) \\
& =\frac{1}{f^{\prime}(\alpha)}\left[1-2 A_{2} \hat{e}_{i}+A_{2}\left(-A_{4}+5 A_{3} A_{2}-5 A_{2}^{3}\right) e_{i}^{4}+O\left(e_{i}^{5}\right)\right],
\end{aligned}
$$

that is 


$$
\begin{aligned}
& F^{\prime}\left(f\left(z_{i}\right)\right) \\
& =\frac{1}{f^{\prime}(\alpha)}\left[1+A_{2}\left(-A_{4}+7 A_{3} A_{2}-7 A_{2}^{3}\right) e_{i}^{4}+O\left(e_{i}^{5}\right)\right],
\end{aligned}
$$

which is same as obtained in Equation (53) of $F^{\prime}\left(f\left(z_{i}\right)\right)=\psi / f^{\prime}\left(x_{i}\right)$. This verifies calculations of error term (55) and $F^{\prime}\left(f\left(z_{i}\right)\right)$.

\section{Remark 6.}

Since $F^{\prime}\left(f\left(z_{i}\right)\right)=\psi / f^{\prime}\left(x_{i}\right)=\left[1 / f^{\prime}(\alpha)\right]\left[1+O\left(\hat{e}_{i}\right)\right]$,

therefore, similar to remark 3 , the iterative formula (48) combined with the Ostrowski iteration (2) verifies the convergence theorem on composition of two iterative functions to produce eighth order iterative method.

\section{Computational Efficiency}

In order to obtain an assessment of the efficiency of our methods we shall make use of Traub's efficiency index ([1], Appendix C), according to which computational efficiency of an iterative method is given by $E=p^{1 / c}$, where $p$ is the order of the method and $c$ is the cost per iterative step of computing the function and derivative required by the iterative formula, that is, $c=\sum c_{j}, c_{j}$ is the cost of evaluating $f^{(j)}$ for $j \geq 0$. The value $j=0$ simply gives the function $f$.

Designating Ostrowski's method (1) as $M_{4}$, sixth order method [4] as $M_{6}$ and present methods (19) and (48) as $M_{8,1}$ and $M_{8,2}$, respectively. Assuming that the cost of evaluating $f^{(j)}$ is 1 , then for $M_{8}$ we find efficiency index $E=8^{1 / 4} \approx 1.682$. For $M_{6}, E=6^{1 / 4}$ $\approx 1.565$ and similarly for $M_{4}, \quad E=4^{1 / 3} \approx 1.587$. Comparing the $\mathrm{E}$ values we find that the present methods are better options than both of $M_{4}$ and $M_{6}$.

\section{Numerical Illustrations}

In this section, we apply the modified methods $M_{8, i}$ $(i=1,2)$ to solve some nonlinear equations, which not only illustrate the methods practically but also serve to check the validity of theoretical results we have derived. The performance is compared with $M_{4}$ and $M_{6}$. In order to compare the higher order methods it becomes necessary that we use higher precision in computations. Therefore, the calculations are performed with high-precision arithmetic and terminated after three iterations. To check the theoretical order of convergence, we obtain the computational order of convergence $(p)$ using the formula (see [7])

$$
p \approx \frac{\ln \left|\left(x_{i+1}-\alpha\right) /\left(x_{i}-\alpha\right)\right|}{\ln \left|\left(x_{i}-\alpha\right) /\left(x_{i-1}-\alpha\right)\right|} .
$$

\begin{tabular}{|c|c|c|c|c|}
\hline Problem & $x_{0}$ & $\left|a-x_{3}\right|$ & $\left|f\left(x_{3}\right)\right|$ & $p$ \\
\hline$f_{1}$ & 1 & & & \\
\hline$M_{4}$ & & $2.21 * 10^{-34}$ & $4.65 * 10^{-33}$ & 4.0 \\
\hline$M_{6}$ & & $7.09 * 10^{-103}$ & $1.49 * 10^{-101}$ & 6.0 \\
\hline$M_{8,1}$ & & $1.18 * 10^{-269}$ & $2.48 * 10^{-268}$ & 8.0 \\
\hline$M_{8,2}$ & & $6.43 * 10^{-204}$ & $7.35 * 10^{-202}$ & 8.0 \\
\hline$f_{2}$ & 1 & & & \\
\hline$M_{4}$ & & $3.50 * 10^{-22}$ & $5.63 * 10^{-22}$ & 4.0 \\
\hline$M_{6}$ & & $4.25 * 10^{-64}$ & $6.83 * 10^{-64}$ & 6.0 \\
\hline$M_{8,1}$ & & $7.26 * 10^{-171}$ & $1.17 * 10^{-170}$ & 8.0 \\
\hline$M_{8,2}$ & & $1.46^{*} 10^{-146}$ & $2.35 * 10^{-146}$ & 8.0 \\
\hline \multicolumn{5}{|l|}{$f_{3}$} \\
\hline$M_{4}$ & & $1.28 * 10^{-78}$ & $1.05 * 10^{-78}$ & 4.0 \\
\hline$M_{6}$ & & $1.03 * 10^{-251}$ & $8.44 * 10^{-252}$ & 6.0 \\
\hline$M_{8,1}$ & & $2.25 * 10^{-635}$ & $1.85 * 10^{-635}$ & 8.0 \\
\hline$M_{8,2}$ & & $3.54 * 10^{-574}$ & $2.90 * 10^{-574}$ & 8.0 \\
\hline$f_{4}$ & 1 & & & \\
\hline$M_{4}$ & & $1.57 * 10^{-29}$ & $4.34 * 10^{-29}$ & 4.0 \\
\hline$M_{6}$ & & $4.42 * 10^{-81}$ & $1.22 * 10^{-80}$ & 6.0 \\
\hline$M_{8,1}$ & & $2.33 * 10^{-298}$ & $6.44 * 10^{-298}$ & 8.0 \\
\hline$M_{8,2}$ & & $1.12 * 10^{-209}$ & $3.10 * 10^{-209}$ & 8.0 \\
\hline$f_{5}$ & 0.5 & & & \\
\hline$M_{4}$ & & $2.21 * 10^{-26}$ & $2.21 * 10^{-26}$ & 4.0 \\
\hline$M_{6}$ & & $2.74 * 10^{-76}$ & $2.74 * 10^{-76}$ & 6.0 \\
\hline$M_{8,1}$ & & $2.53 * 10^{-232}$ & $2.53 * 10^{-232}$ & 8.0 \\
\hline$M_{8,2}$ & & $2.85 * 10^{-191}$ & $2.85 * 10^{-191}$ & 8.0 \\
\hline$f_{6}$ & 2 & & & \\
\hline$M_{4}$ & & $5.44 * 10^{-32}$ & $1.35 * 10^{-31}$ & 4.0 \\
\hline$M_{6}$ & & $2.98 * 10^{-95}$ & $7.40 * 10^{-95}$ & 6.0 \\
\hline$M_{8,1}$ & & $1.10 * 10^{-268}$ & $2.72 * 10^{-268}$ & 8.0 \\
\hline$M_{8,2}$ & & $9.17 * 10^{-212}$ & $2.28 * 10^{-211}$ & 8.0 \\
\hline$f_{7}$ & 1 & & & \\
\hline$M_{4}$ & & $1.62 * 10^{-36}$ & $4.93 * 10^{-36}$ & 4.0 \\
\hline$M_{6}$ & & $4.17^{*} 10^{-108}$ & $1.27 * 10^{-107}$ & 6.0 \\
\hline$M_{8,1}$ & & $1.00 * 10^{-269}$ & $3.04 * 10^{-269}$ & 8.0 \\
\hline$M_{8,2}$ & & $5.13^{*} 10^{-236}$ & $1.56 * 10^{-235}$ & 8.0 \\
\hline$f_{8}$ & -1.5 & & & \\
\hline$M_{4}$ & & $2.30 * 10^{-39}$ & $4.68 * 10^{-38}$ & 4.0 \\
\hline$M_{6}$ & & $1.36 * 10^{-108}$ & $2.76^{*} 10^{-107}$ & 6.0 \\
\hline$M_{8,1}$ & & $2.83 * 10^{-231}$ & $5.75 * 10^{-230}$ & 8.0 \\
\hline$M_{8,2}$ & & $2.11 * 10^{-233}$ & $4.28 * 10^{-232}$ & 8.0 \\
\hline
\end{tabular}

We consider the following test problems:
Table 1. Performance of methods. 


$$
\begin{aligned}
& f_{1}(x)=x^{3}+4 x^{2}-15, \quad \alpha=1.6319808055660636, \\
& f_{2}(x)=x^{2}-(1-x)^{5}, \quad \alpha=0.3459548158482420, \\
& f_{3}(x)=\sin (x)-x / 2, \quad \alpha=1.8954942670339809, \\
& f_{4}(x)=10 x \exp \left(-x^{2}\right)-1, \quad \alpha=1.6796306104284499, \\
& f_{5}(x)=x^{3}+\log (1+x), \quad \alpha=0, \\
& f_{6}(x)=\sin ^{2}(x)-x^{2}+1, \quad \alpha=1.4044916482153412, \\
& f_{7}(x)=\cos (x)-x e^{x}, \quad \alpha=0.51775736368245830, \\
& f_{8}(x)=x e^{x^{2}}-\sin ^{2} x+3 \cos x+5, \\
& \alpha=-1.2076478271309189 .
\end{aligned}
$$

Table 1 shows the absolute difference $\left|\alpha-x_{3}\right|$, the absolute value of the function $\left|f\left(x_{3}\right)\right|$ and the computational order of convergence $(p)$. It can be observed clearly that in all considered test problems, the new methods $M_{8, i} \quad(i=1,2)$ compute the results with higher precision than $M_{4}$ and $M_{6}$. This superiority of $M_{8, i}$ agrees with theoretical analysis of order and efficiency discussed in previous sections.

\section{Conclusions}

In this work, we have obtained two multipoint methods of order eight using an additional evaluation of function at the point iterated by Ostrowski's method of order four for solving equations. Thus, one requires three evaluations of the function $f$ and one of its first-derivative $f^{\prime}$ per full step and therefore, the efficiency of the methods is better than Ostrowski's method. The superiority of present methods is also corroborated by numerical results displayed in the table 1 . The computational order of convergence $(p)$ overwhelmingly supports the eighth order convergence of our methods. These methods also provide the examples of eighth order methods requiring four evaluations for Kung and Traub conjecture. Finally, we conclude the paper with the remarks that such higher order methods are useful in the numerical applications requiring high precision in their computations.

\section{References}

[1] J. F. Traub, "Iterative Methods for the Solution of Equations,” Prentice Hall, Englewood Cliffs, 1964.

[2] H. T. Kung and J. F. Traub, "Optimal Order of One-Point and Multipoint Iteration," Journal of the Association for Computing Machinery, Vol. 21, No. 4, 1974, pp. 643-651. doi: $10.1145 / 321850.321860$

[3] A. M. Ostrowski, "Solutions of Equations and System of Equations,” Academic Press, New York, 1960.

[4] M. Grau and J. L. Díaz-Barrero, "An Improvement to Ostrowski Root-Finding Method,” Applied Mathematics and Computation, Vol. 173, No. 1, 2006, pp. 450-456. doi:10.1016/j.amc.2005.04.043

[5] J. R. Sharma and R. K. Guha, "A Family of Modified Ostrowski Methods with Accelerated Sixth Order Convergence," Applied Mathematics and Computation, Vol. 190, No. 1, 2007, pp. 111-115. doi:10.1016/j.amc.2007.01.009

[6] G. M. Phillips and P. J. Taylor, "Theory and Applications of Numerical Analysis,” Academic Press, New York, 1996.

[7] S. Weerakoon and T. G. I Fernando, “A Variant of Newton's Method with Accelerated Third-Order Convergence,” Applied Mathematics Letters, Vol. 13, No. 8, 2000, pp. 87-93. doi:10.1016/S0893-9659(00)00100-2 